\title{
Cross-sectional and Longitudinal Epidemiologic Surveys of Human and Canine Leishmania infantum Visceral Infections in an Endemic Rural Area of Southeast Brazil (Pancas, Espírito Santo)
}

\author{
Aloísio Falqueto, Adelson L. Ferreira, Claudiney B. dos Santos, Renato Porrozzi, Marcos V. Santos da Costa, \\ Antonio Teva, Elisa Cupolillo, Antonio Campos-Neto, and Gabriel Grimaldi Jr* \\ Laboratório de Pesquisa em Leishmaniose, Instituto Oswaldo Cruz, Rio de Janeiro, RJ, Unidade de Medicina Tropical, Universidade \\ Federal do Espírito Santo, Vitória, ES, Brazil; The Forsyth Institute, Boston, Massachusetts
}

\begin{abstract}
In an endemic rural area of southeast Brazil, surveys confirmed that dogs serve as peridomestic reservoirs of Leishmania infantum. It is likely that the lack of efficient control is because presently used diagnostic tests miss positive dogs. Overall, $57 \%$ of the dogs had specific antibodies, but the canine infection was not uniformly fatal and many seropositive dogs remained asymptomatic or even spontaneously recovered. Furthermore, $42 \%$ of the human residents became leishmanin-positive reactors and $47 \%$ had positive serology at the initial survey, but our estimates also point at a high recovery rate among the infected population with time. The delayed-type hypersensitivity (DTH) reaction to Leishmania was a good indicator of resistance to infection in this particular epidemiologic situation. The lack of any significant differences in infection rates by gender or age indicate that all of the population was at an equal risk of infection and most people were infected in the peridomestic setting.
\end{abstract}

\section{INTRODUCTION}

In the Neotropics, zoonotic visceral leishmaniasis (VL) caused by Leishmania infantum (syn. L. chagasi) is transmitted by the phlebotomine sand fly Lutzomyia longipalpis (Diptera:Psycodidae). Foxes (Cerdocyon thous and Lycalopex vetulus) and domestic dogs are the major vertebrate reservoirs of the parasite. The infection is widely distributed in Central and South America, from Mexico to Argentina, but more than $90 \%$ of VL cases reported in the New World have occurred in Brazil, ${ }^{1}$ where a total of 51,222 cases were officially recorded between 1980 and 2003. From a public health viewpoint, the most important epidemiologic aspects of VL distribution in Brazil are that the number of reported cases is increasing (since 2003, the estimated annual incidence of $\mathrm{VL}$ is $\approx 4000$ ), and new foci are continually emerging (http:// portal.saude.gov.br/portal/arquivos/pdf/manual_leish_ visceral 2006.pdf).

In areas of high transmission, the parasite is probably maintained largely in domestic dog populations. ${ }^{2,3}$ The clinical expression of L. infantum infection in dogs is highly variable, depending on the immune status of the host ${ }^{4}$ and other genetic factors influencing canine susceptibility to VL. 5,6 Severely affected dogs do not survive the disease, although subclinical infections with L. infantum may occur commonly in dogs $\mathrm{s}^{4,7}$ as they do in humans. ${ }^{8,9}$ Hence, the prevalence and the incidence of canine visceral leishmaniasis (CVL) are important epidemiologic parameters for controlling transmission, the estimation of which depends on the reliable identification of infected dogs. ${ }^{10}$ Because of the limitations of direct methods to detect parasites in dogs (either by microscope examination, culture, or the inoculation of hamsters with biopsy specimens), antibody-based tests are routinely used as a marker of infection. ${ }^{3,11}$ Others like polymerase chain reaction (PCR)based assays have also been used for detecting L. infantum DNA in diagnostic samples from humans ${ }^{12}$ and dogs, ${ }^{13,14}$ but

\footnotetext{
*Address correspondence to Gabriel Grimaldi Jr., Laboratório de Pesquisa em Leishmaniose, Instituto Oswaldo Cruz, IOC/Fiocruz, Pavilhão Leônidas Deane, Sala 509, Av. Brasil 4365, 21045-090 Rio de Janeiro, RJ, Brazil. E-mail: grimaldi@ioc.fiocruz.br
}

they are most useful for detecting active infection, whereas serology can be a more sensitive technique for detection of all infected dogs. ${ }^{13,15}$

Visceral leishmaniasis in Espírito Santo (southeast Brazil) was first recorded in 1968, and since then several cases associated with L. infantum in humans and dogs have been reported. ${ }^{1}$ Between 1980 and 2000, 110 cases of human VL occurred in the northwestern part of the state (municipalities of Pancas, Águia Branca, São Gabriel da Palha, Nova Venécia, Água Doce do Norte, Governador Lindenberg, Baixo Guandu, Itaguaçu, Itarana, and São Roque do Canaã). Moreover, $8.7 \%$ of a sample $(91 / 1,045)$ of local dogs were seropositive in 2001 (Falqueto A and others, unpublished data). Because the prevalence of CVL appeared to be increasing in Pancas, we decided to research the current status of infection and disease in the area. The principal aims were 1) to evaluate how many people had been in contact with L. infantum in an area of canine infection, 2) to research if the prevalence of human infection was associated with that of CVL, and 3) to identify the demographic risk factors for infection (to indicate whether transmission in an endemic rural area typically takes place inside or away from the domestic environment). We have chosen to use enzyme-linked immunosorbent assay (ELISA)-based methods for the detection of antibodies against crude and recombinant leishmanial antigens for our surveys, because these assays reach an overall sensitivity of $100 \%$ when these antigens are used in parallel, as shown herein and elsewhere. ${ }^{15}$

\section{MATERIALS AND METHODS}

Study design. Between 2003 and 2004, a prospective field study was carried out in an endemic rural area located in the municipality of Pancas, Espírito Santo State (Brazil). Pancas, situated at $19^{\circ} 13^{\prime} 10^{\prime \prime} \mathrm{S}$ and $40^{\circ} 51^{\prime} 11^{\prime \prime} \mathrm{W}$, is $125 \mathrm{~km}$ from the Atlantic Ocean and $200 \mathrm{~m}$ above sea level. The ecologic zone is designated as dry subtropical forest, with an annual average temperature of $22.5^{\circ} \mathrm{C}$ and yearly rainfall of $1,219 \mathrm{~mm}$. The data were collected in a small community located $20 \mathrm{~km} \mathrm{NE}$ of the town of Pancas. A single unpaved road, $\approx 15 \mathrm{~km}$ long, provides access to four small, scattered settlements made up 
of 56 well-dispersed houses and with space between houses occupied by coffee and banana plantations. Most of the houses in the community are situated along four streams, named

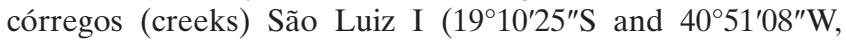
altitude $=380$ meters $)$, Palmital $\left(19^{\circ} 12^{\prime} 26^{\prime \prime} \mathrm{S}\right.$ and $40^{\circ} 47^{\prime} 46^{\prime \prime} \mathrm{W}$, altitude $=395$ meters $)$, Roque $\left(19^{\circ} 05^{\prime} 30^{\prime \prime} \mathrm{S}\right.$ and $40^{\circ} 51^{\prime} 27^{\prime \prime} \mathrm{W}$, altitude $=216$ meters $)$, and Ubá $\left(19^{\circ} 04^{\prime} 75^{\prime \prime} \mathrm{S}\right.$ and $40^{\circ} 50^{\prime} 13^{\prime \prime} \mathrm{W}$, altitude $=99$ meters). These streams run near rocky mountain areas that are heavily deforested, but show a few remnants of the original vegetation. Most men, and many women, work in coffee plantations. Immigration and emigration from the area are common, but the immigrants are commonly relatives of the residents. The study area was mapped, houses were identified by numbers, and appropriate measures were adopted for follow-up.

The first survey took place in October of 2003. All of the eligible persons $(\approx 250)$ were invited to participate in the study. Of these, 186 (74\%) agreed to give blood and 201 agreed to be skin tested with leishmanin ( $80 \%)$. Indigenous dogs numbered 109. Blood samples were obtained from each dog with verbal agreements from the animal owners. Serologic tests (indirect fluorescence antibody test [IFAT] and/or ELISA) were applied on the sera from humans and dogs for detecting circulating specific antibodies. This was combined with clinical screening and leishmanin skin tests (LSTs) administered to all participants of the study. The second survey followed the same procedure, and was carried out after an interval of 12 months (November of 2004). Tables 4, 5, and 8 give the numbers of people and dogs that were examined by each test in the second survey.

Clinical examination. Demographic data were recorded for each family member, including age, sex, occupation, and position in the family, along with any current or previous history of clinical VL (fever, cough, diarrhea, weight loss). All consenting sero- and/or leishmanin-positive subjects were examined by a physician. Furthermore, all dogs underwent gross physical examinations in the field by veterinary practitioners. Animals were scored clinically for 6 typical signs of CVL (alopecia, dermatitis, chancres, conjunctivitis, lymphadenopathy, onychogryphosis) on a semi-quantitative scale as previously described. ${ }^{15}$

Diagnostic criteria and tests. Leishmanin skin testing. The leishmanin antigen used for skin testing of the local human population was provided by the Fiocruz, Biomanguinhos Unit (Rio de Janeiro, Brazil), which consisted of a soluble extract of Leishmania amazonensis promastigotes (IFLA/ BR/1967/PH8) containing $25 \mu \mathrm{g}$ of leishmanial proteins. All consenting villagers were inoculated intradermically in the right forearm with disposable tuberculin syringes $(0.1 \mathrm{~mL})$. The size of the skin induration was measured from 48 to 72 hours later using the roller-ball procedure described by Sokal. ${ }^{16}$ Induration of $5 \mathrm{~mm}$ or more was considered a positive reaction.

Enzyme-linked immunosorbent assays. Sera from humans and dogs were analyzed by standard micro-ELISA ${ }^{17}$ to detect specific antibodies against crude and recombinant leishmanial antigens. Promastigotes of L. infantum isolated from a local dog provided the source of whole-parasite extracts. A preparation of crude soluble antigen (CSA), derived from promastigotes broken by ultrasonic treatment, was made as described elsewhere. ${ }^{15}$ The two recombinant antigens of $L$. infantum, namely the rK39 (a 39-aminoacid-repetitive immunodominant B-cell epitope kinesin-related antigen) ${ }^{18}$ and rK26 (a gene fragment product containing the repetitive sequence of K26), ${ }^{19}$ were kindly provided by the Infectious Disease Research Institute, Seattle, Washington. All ELISA procedures were optimized with regard to the antigen concentrations and the serum dilutions. Optimal antigen concentrations were $2 \mu \mathrm{g} / \mathrm{mL}$ for CSA and $0.5 \mu \mathrm{g} / \mathrm{mL}$ for each recombinant protein. Optimal serum dilution was 1:600. Commercially prepared peroxidase-labeled rabbit antiserum to either human or canine immunoglobulins G (whole molecule; Sigma, St. Louis, MO) was used as the conjugate. The substrate consisted of $0.04 \% o$-phenyllenediamine dihydrochloride and $0.012 \%$ hydrogen peroxidase in phosphate-citrate buffer with a $\mathrm{pH}$ of 5.0. Absorbance was measured at $492 \mathrm{~nm}$ in an E max microplate reader (Molecular Devices, Ramsey, Minnesota, MN). All sera were tested in duplicate and those yielding positive results were retested at least once. Sera considered to be truly parasite positive, along with negative-control sera (from healthy blood donor humans or pets born in a VL-free area of Brazil), were included in each test. The lower limit of positivity (cut off) was determined by the mean plus 3 standard deviations of the $A_{492}$ values of 25 normal controls.

Indirect fluorescence antibody test. The IFAT was carried out according to standard procedures, ${ }^{20}$ using cultured promastigotes adsorbed to microscope slides as the antigen. Sera were prepared from eluates from dogs blood collected on filter paper and diluted 1:40-1:320. Goat anti-dog IgGfluorescein (whole molecule; Sigma, St. Louis, MO) diluted at 1:80 was used as the conjugated detecting antibody. Positive and negative control sera were tested on each slide. Samples were classified positive if promastigote cytoplasmatic or membrane fluorescence was observed at a serum dilution of $\geq 1: 40$.

Sampling and parasitology. When a positive IFAT was obtained, or amastigotes were observed in a Giemsa-stained direct smear of bone marrow specimens, the infected dog was euthanized (as recommended by the Brazilian National Health Foundation, FUNASA) and its liver and spleen were removed for culture and for histopathologic examination. Before each sampling, dogs were anaesthetized with 20-mg ketamine hydrochloride (Vetalar)/kg body weight, injected intramuscularly. Then $10 \mathrm{~mL}$ of venous blood were taken by venipuncture. Bone marrow was aspirated from the iliac crest with a $16 \mathrm{~mm} \times 25 \mathrm{~mm}$ needle into a 20 -mL syringe containing $0.5 \%$ EDTA. The sample was then used to make methanol-fixed Giemsa-stained smears for direct microscopic examination. Paraffin sections from necropsy tissues samples (fixed in $10 \%$ neutral buffered formalin) were stained with haematoxylin-eosin for histopathologic examination. Organ specimens from infected dogs were also removed aseptically at necropsy, triturated in phosphate-buffered saline containing gentamycin $(40 \mu \mathrm{g} / \mathrm{mL})$, and inoculated directly into tubes of NNN blood-agar medium containing an overlay of Schneider's Drosophila medium (Sigma, St. Louis, MO), supplemented with $10 \%$ heat-inactivated $\left(60^{\circ} \mathrm{C}\right.$ for 20 minutes) fetal bovine serum (FBS) and intraperitoneal (IP) injection into Syrian hamsters. ${ }^{1}$ Parasites isolated from primary organ cultures in NNN medium were transferred to flasks of Schneider's medium containing 20\% FBS and gentamycin $(40 \mu \mathrm{g} / \mathrm{mL})$, and incubated at $25^{\circ} \mathrm{C}$. Promastigotes were grown in mass culture to provide samples for subsequent identification by isoenzyme analysis. If the primary 
TABLE 1

Comparison of leishmanin skin test (LST) and enzyme-linked immunosorbent assays (ELISAs) as screening tests for human Leishmania infantum infection (Pancas, ES, Brazil; 2003)

\begin{tabular}{|c|c|c|c|c|c|}
\hline \multirow[b]{2}{*}{ Study sites* } & \multicolumn{5}{|c|}{ No. positive/total tested ( $\%$ positive) by } \\
\hline & $\mathrm{LST}^{\dagger}$ & Total ELISA $\doteqdot$ & CSA ELISA & K26 ELISA & K29 ELISA \\
\hline SL & $23 / 46(50)$ & $18 / 40(45)$ & $14 / 40(35)$ & $6 / 40(15)$ & $11 / 40(28)$ \\
\hline $\mathrm{P}$ & $12 / 48(25)$ & $14 / 47(30)$ & $14 / 47(30)$ & $3 / 47(6)$ & $4 / 47(9)$ \\
\hline $\mathrm{R}$ & $13 / 51(25)$ & $23 / 50(46)$ & $9 / 50$ (18) & $15 / 50(30)$ & $14 / 50(28)$ \\
\hline $\mathrm{U}$ & $36 / 56(64)$ & $32 / 49(65)$ & $10 / 49(22)$ & $25 / 49(51)$ & $14 / 49$ (29) \\
\hline Total & $84 / 201(42)$ & $87 / 186$ (47) & 47/186 (25) & 49/186 (26) & $43 / 186(23)$ \\
\hline
\end{tabular}

NNN culture was negative, then the hamster inoculated with the corresponding tissue sample was euthanized after 3 to 6 months. A sterile homogenate of its spleen was inoculated into another set of NNN tube cultures. Positive culture containing promastigotes were then expanded for growth in Schneider's medium and identified by isoenzyme analysis.

Identification of parasites. The isolated strains were characterized by multi-locus enzyme electrophoresis (MLEE). The methods used to prepare samples and study the electrophoretic mobility of some enzymes in agarose gels were performed as previously reported. ${ }^{21}$ Samples were tested for the activity of the following enzymes: aconitate hydratase (ACON, E.C.4.2.1.3), glucose-6-phosphate dehydrogenase (G6PDH, E.C.1.1.1.49), glucose phosphate isomerase (GPI, E.C.5.3.1.9), isocitrate dehydrogenase NAD and NADP (IDHNAD \& IDHNADP, E.C.1.1.1.42), malate dehydrogenase (MDH, E.C.1.1.1.37), malic enzyme (ME, E.C.1.1.1.40), manose phosphate isomerase (MPI, E.C.5.3.1.8), nucleosidase (NH1 \& NH2, E.C.3.2.2.1), 6-phospho-gluconate dehydrogenase (6PGDH, E.C.1.1.1.43), phospho-glucomutase (PGM, E.C.1.4.1.9), leu-pro dipeptidase (PEPD, 3.4.13.9), and leu-gly dipeptidase (PEP2, E.C.3.4.11.1).

Statistical analysis. The association between results (positive-negative), obtained by LS and ELISA for the detection of leishmanial infection in humans, was determined by the Fisher's exact test. Seroprevalence among dog sex subsets, and sensitivity differences between the ELISAs and IFAT, were also compared by the $\chi^{2}$ test and a $P$ value of $<0.05$ was considered statistically significant.

Ethical considerations. This research has complied with all relevant Brazilian federal guidelines (Projeto de lei 3.964/97www.planalto.gov.br). Informed consent was obtained from all human adult participants and from parents of legal guardians of minors, and permission was also obtained from all householders to use their dogs. The Ethics Committee of CEP/ FIOCRUZ and UFES sanctioned all clinical and experimental procedures.

\section{RESULTS}

Prevalence of human infection. Of the 201 leishmanin-tested individuals of various ages (representing $80 \%$ of the residents in the community who had been cured of VL $[N=6]$ or with no history of the disease) in 2003, 84 (42\%) had a positive skin test (i.e., with indurations $\geq 5 \mathrm{~mm}$ after 48 to 72 hours), but the proportion of leishmanin-positive inhabitants varied considerably in the contiguous localities, ranging from $25 \%$ to $64 \%$
(Table 1). The LST reaction sizes found among positive subjects were variable (range 3-30 mm). No statistical differences $(P=0.40)$ in the skin in duration diameters could be demonstrated between LST-1 (mean \pm SE $10.1 \pm 5.6$ ) and LST-2 $(11.1 \pm 9.3)$. The prevalence of skin test positivity increased in the older/longer-exposed segment of the population (infection rates in the age groups of $<10$ and $\geq 45$ years were $19 \%$ and $44 \%$, respectively), but it was not strongly related to gender (Table 2). Overall, 47\% of the subjects (87/186) were found to have specific anti-Leishmania IgG antibodies (ELISA) and the seroprevalences were highly variable in the study localities, ranging from $30 \%$ to $65 \%$ (Table 1 ). In contrast, the proportion of seropositive persons did not vary significantly $(P>0.05)$ according to age or gender (Table 3$)$, thus indicating that transmission of L. infantum to people in our study area is most abundant peridomestically rather than in forest patches. None of the 100 individuals sensitized to L. infantum (i.e., leishmanin- and/or sero-positive) for whom a clinical history was recorded at both surveys developed clinical VL. It should be noted that poorly-nourished individuals (a condition that, in general, facilitates disease pathology) were not identified by clinical examination within the study period.

The results show a variation in reversion rates with time in a number of villagers with cutaneous DTH reaction to Leishmania (Table 4) and serum levels of anti-leishmanial antibodies (Table 5), indicating that they developed nonapparent self-healing infections. Although DTH and serology conversion rates (from a negative to a positive response) were comparable (both 14\%) among people tested in both surveys, the DTH reversion rate (from a positive to a negative LST response) was much lower (0.38) as compared with the serology reversion rate $(0.62)$. The cross-sectional analysis showed a negative association between the LST and

TABLE 2

Variation in the proportion of individuals with positive leishmanin skin test (LST) shown by age-group and gender (Pancas, ES, Brazil; 2003)

\begin{tabular}{|c|c|c|c|}
\hline \multirow[b]{2}{*}{ Age (in years) } & \multicolumn{3}{|c|}{ No. positive/total tested by LST } \\
\hline & Males & Females & $\begin{array}{c}\text { No. } \\
\text { positive/age-group }\end{array}$ \\
\hline$<10$ & $2 / 10$ & $3 / 16$ & $0.19(5 / 26)$ \\
\hline$<15$ & $6 / 21$ & $10 / 29$ & $0.32(16 / 50)$ \\
\hline$<45$ & $34 / 75$ & $27 / 74$ & $0.41(61 / 149)$ \\
\hline$\geq 45$ & $16 / 28$ & $7 / 24$ & $0.44(23 / 52)$ \\
\hline No. positive/gender*† & $0.49(50 / 103)$ & $0.35(34 / 98)$ & - \\
\hline
\end{tabular}


TABLE 3

Variation in the proportion of individuals with anti-leishmanial antibodies shown by age-group and gender (Pancas, ES, Brazil; 2003)

\begin{tabular}{cccc}
\hline & \multicolumn{3}{c}{ No. positive/total tested by ELISA } \\
\cline { 2 - 4 } Age (in years) & Males & Females & $\begin{array}{c}\text { No. } \\
\text { positive/age-group* }\end{array}$ \\
\hline$<10$ & $2 / 9$ & $9 / 14$ & $0.48(11 / 23)$ \\
$<15$ & $7 / 20$ & $16 / 27$ & $0.49(23 / 47)$ \\
$<45$ & $30 / 72$ & $40 / 70$ & $0.49(70 / 142)$ \\
$\geq 45$ & $8 / 24$ & $9 / 20$ & $0.39(17 / 44)$ \\
No. positive/gender* $\dagger$ & $0.40(38 / 96)$ & $0.54(49 / 90)$ & -
\end{tabular}

* There was no statistically significant difference $\left(\chi^{2}\right.$ test, $\left.P>0.05\right)$ in the seroprevalence of specific antibodies between age- or gender-groups.

$\uparrow$ Total numbers of individuals in each gender group (96 and 90) are the cumulative numbers of all $<45$ - and $>45$-year-old individuals.

ELISA results (Table 6). Among a total of 110 leishmaninpositive village inhabitants, $29(26 \%)$ had a positive ELISA response, but no concordance was found between the LST reaction size values and antibody levels $(r=0.26 ; P=0.53)$. In contrast, of the 91 people with a negative LST response, $38(42 \%)$ showed a positive serology. Moreover, out of 72 subjects with a negative LST-1 response who were retested at the second survey, 10 became leishmanin-positive reactors but all remained seronegative. Conversely, 27\% (17/62) of the individuals with a negative LST-2 response became seropositive at this time.

Detection of anti-Leishmania antibodies in dogs. Table 7 summarizes the results of the different ELISAs used in this comparative study with the classic diagnostic test (IFAT) for detecting anti-Leishmania antibodies. The sensitivities of ELISAs based on CSA (72\%) and the rK39 and rK26 proteins (84 and 91\%, respectively) were remarkably higher $(P<0.001)$ than that of an IFAT $(35 \%)$. Moreover, the ELISA assays detected all dogs with proven symptomatic and asymptomatic L. infantum infections (100\% sensitivity) when these antigens were used in parallel. Overall, $57 \%$ of the dogs (62/109) had anti-Leishmania antibodies (ELISA), but the seroprevalences through contiguous localities ranged from $42 \%$ to $76 \%$. There were no statistically significant differences $\left(\chi^{2}=0.193 ; P=0.66\right)$ in sex distribution between the infected (seropositive) and non-infected (seronegative) dogs (data not shown). During the study period, a proportion of the seropositive dogs developed clinical signs of canine VL (such as alopecia, dermatitis, chancres, conjunctivitis, onychogryphosis, and/or lymphadenopathy), which were arbitrarily classified as polisymptomatic $(16 \%)$ or oligosymptomatic $(26 \%)$, whereas

TABLE 4

Proportion of individuals with cutaneous delayed-type hypersensitivity (DTH) reaction to Leishmania antigens reverting from positive 4(LST-1) to negative (LST-2) by age-group and gender (Pancas, ES, Brazil)

\begin{tabular}{cccc}
\hline & \multicolumn{3}{c}{ No. reverted/no. positive at LST-1 } \\
\cline { 2 - 4 } Age (in years) at LST-1 & Males & Females & Proportion reverted \\
\hline$<10$ & $1 / 2$ & $0 / 3$ & $0.20(1 / 5)$ \\
$<15$ & $1 / 4$ & $3 / 9$ & $0.30(4 / 13)$ \\
$<45$ & $9 / 24$ & $9 / 29$ & $0.34(18 / 53)$ \\
$\geq 45$ & $6 / 16$ & $6 / 11$ & $0.45(12 / 27)$ \\
Proportion reverted* $^{*}$ & $0.38(15 / 40)$ & $0.38(15 / 40)$ & $0.38(30 / 80)$ \\
\hline
\end{tabular}

* Total numbers of individuals in each gender group (40 and 40) are the cumulative numbers of all $<45$ - and $\geq 45$-year-old individuals.

Note: The proportion of cases converting from negative LST-1 (initial survey in 2003) to positive LST-2 (second survey in 2004) was $0.14(11 / 80)$.
TABLE 5

Proportion of individuals with anti-leishmanial antibodies reverting from positive (ELISA-1) to negative (ELISA-2) by age-group and gender (Pancas, ES, Brazil)

\begin{tabular}{cccc}
\hline & \multicolumn{3}{c}{ No. reverted/no. positive at ELISA-1 } \\
\cline { 2 - 4 } Age (in years) at LST-1 & Males & Females & Proportion reverted \\
\hline$<10$ & $0 / 2$ & $8 / 9$ & $0.73(8 / 11)$ \\
$<15$ & $4 / 7$ & $14 / 16$ & $0.78(18 / 23)$ \\
$<45$ & $18 / 28$ & $25 / 37$ & $0.66(43 / 65)$ \\
$\geq 45$ & $6 / 9$ & $2 / 8$ & $0.47(8 / 17)$ \\
Proportion reverted* & $0.65(24 / 37)$ & $0.60(27 / 45)$ & $0.62(51 / 82)$ \\
\hline
\end{tabular}

* Total numbers of individuals in each gender group (37 and 45) are the cumulative numbers of all $<45$ - and $\geq 45$-year-old individuals.

Note: The proportion of cases converting from negative ELISA-1 (initial survey in 2003) to Note: The proportion of cases converting from negative
positive ELISA-2 (second survey in 2004) was $0.14(12 / 85)$.

$58 \%$ of the cases remained asymptomatic. The proportion of dogs converting from a negative (ELISA-1) to positive serology (ELISA-2) was twice as high as that of cases reverting from a positive to negative serology (Table 8), thus revealing the continuing occurrence of transmission in these highly endemic foci of VL.

Parasite identification. During both the cross-sectional and longitudinal serodiagnostic surveys, L. infantum visceral infection was ascertained in 43 seropositive dogs by the demonstration of the presence of the parasite in Giemsa-stained smears and/or in vitro cultures of the dogs' tissue specimens. The necropsy findings also showed parasite-containing macrophages in the skin, liver, and/or spleen. A total of $25 \mathrm{dog}$ isolates were obtained, all by hamster inoculation. Isoenzymatic characterization showed that these isolates (representing parasites from all study foci) were identified as L. infantum zymodeme IOC-Z1.

\section{DISCUSSION}

The DTH reaction to Leishmania antigen is a good indicator of endemicity as it correlates with human VL incidence ${ }^{22}$ and seroprevalence of canine Leishmania infection. ${ }^{23}$ This study confirms that Pancas is a highly endemic rural area of L. infantum activity, as determined by LST (the overall leishmanin positivity rate was $42 \%$ ) and/or quantitative serologic tests (the prevalences of specific antibodies were $47 \%$ and $57 \%$ in the local human and dog populations, respectively). These data also suggest that subclinical infection in humans must be common, because only a few of the $27 \mathrm{VL}$ cases reported in the state occurred in Pancas residents between

TABLE 6

Association between parasite-specific cellular (LST) and humoral (antibodies) responses in asymptomatic humans exposed to natural Leishmania infantum infection (Pancas, ES, Brazil)

\begin{tabular}{cccc}
\hline & & \multicolumn{2}{c}{$\begin{array}{c}\text { Leishmania-specific (IgG) } \\
\text { antibodies (ELISA) }\end{array}$} \\
\cline { 3 - 4 } Study & LST & $\begin{array}{c}\text { No. } \\
\text { positive }(\%)\end{array}$ & $\begin{array}{c}\text { No. } \\
\text { negative }(\%)\end{array}$ \\
\hline Cross-sectional & Positive $(N=110)$ & $29(26)$ & $81(74)$ \\
survey* $\$$ & Negative $(N=91)$ & $38(42)$ & $53(58)$ \\
Longitudinal & Positive $(N=10)$ & $0(0)$ & $10(100)$ \\
survey $\$ \S$ & Negative $(N=62)$ & $17(27)$ & $45(73)$
\end{tabular}

* Status at LST-1 (in 2003) or LST-2 (in 2004); when tested twice, result at LST-2 was used. $\dagger$ Status at LST-2 for the 72 subjects who were negative at LST-1 and who were re-tested. \# Significant association between LST and ELISA results $(P=0.02)$.

$\S$ Not significant association between LST and ELISA results $(P=0.10)$ 
TABLE 7

Comparative sensitivities of ELISAs and IFAT for detection of anti-leishmanial antibodies in canine sera† (Pancas, ES, Brazil; 2003)

\begin{tabular}{|c|c|c|c|c|c|}
\hline \multirow[b]{2}{*}{ Study sites } & \multicolumn{5}{|c|}{ No. positive/total tested ( $\%$ positive) by } \\
\hline & Total ELISA $\ddagger$ & K26 ELISA & K39 ELISA & CSA ELISA & IFAT \\
\hline SL & $18 / 36(50)$ & $16 / 36(44)$ & $14 / 36(39)$ & $7 / 36(19)$ & $4 / 33(12)$ \\
\hline $\mathrm{P}$ & $8 / 19(42)$ & $3 / 19(16)$ & $2 / 19(11)$ & $4 / 19(21)$ & $1 / 19(5)$ \\
\hline $\mathrm{R}$ & $17 / 29(59)$ & $13 / 29(45)$ & $10 / 29(34)$ & $10 / 29(34)$ & $3 / 29(10)$ \\
\hline $\mathrm{U}$ & $19 / 25(76)$ & $11 / 25(44)$ & $7 / 25(28)$ & $15 / 25(60)$ & $4 / 25(16)$ \\
\hline Total & $62 / 109(57)$ & 43/109 (39) & $33 / 109(30)$ & $36 / 109(33)$ & 12/106 (11) \\
\hline Test sensitivity§ & $43 / 43(100)$ & $39 / 43(91)^{*}$ & $36 / 43(84) *$ & $31 / 43(72) *$ & $15 / 43(35)$ \\
\hline
\end{tabular}

1999 and 2000 (http://portal.saude.gov.br/portal/arquivos/ pdf/manual_leish_visceral2006.pdf). Comparable results were obtained by other researchers during epidemiologic studies in different endemic areas. ${ }^{8,9,24-26}$ Because both visceral and cutaneous leishmaniasis (CL) occur in Pancas, ${ }^{27}$ potential cross-reacting immune responses could have occurred in some of the leishmanin-tested individuals. However, the following facts provide a basis to validate our conclusions: 1) although CL associated with Leishmania braziliensis (i.e., based on clinical descriptions of human and canine cases and parasite isolations) is apparently an urban disease in Pancas, no human or canine case of the disease has been recorded in the studied foci; 2) L. infantum was the only species found infecting dogs within the study period; and 3) accordingly, there was a clear correlation between human infection and the relatively high prevalence and distribution of the L. infantum infection in dogs. Moreover, results similar to ours have been previously reported by other researchers ${ }^{22,25}$ after studying asymptomatic L. infantum-infected subjects living in endemic areas where L. braziliensis CL does not occur.

In our study, different age profiles were obtained for LST and ELISA results (Tables 2 and 3), which are in agreement with observations of other groups. ${ }^{8,26}$ It is well known that the in vivo persistence of antigen and its tissue distribution contribute to the duration of immune memory. ${ }^{28}$ One could speculate that the increased numbers of LST-positive in older individuals result from a sustained Th1-mediated response, whereas the age-independent variation in those seropositive individuals is more likely related to shortterm antibody responses occurring during the early stage

TABLE 8

Proportion of dogs with anti-leishmanial antibodies reverting from positive (ELISA-1) to negative (ELISA-2) by gender and study site (Pancas, ES, Brazil)

\begin{tabular}{lccc}
\hline \multirow{2}{*}{ Study sites } & \multicolumn{3}{c}{ No. reverted/no. positive at ELISA-1 } \\
\cline { 2 - 4 } & Males & Females & Proportion reverted \\
\hline $\mathrm{SL}$ & $5 / 14$ & $4 / 4$ & $0.50(9 / 18)$ \\
$\mathrm{P}$ & $2 / 3$ & $0 / 4$ & $0.29(2 / 7)$ \\
$\mathrm{R}$ & $2 / 16$ & $0 / 1$ & $0.12(2 / 17)$ \\
$\mathrm{U}$ & $2 / 10$ & $3 / 9$ & $0.26(5 / 19)$ \\
Proportion reverted & $0.26(11 / 43)$ & $0.39(7 / 18)$ & $0.30(18 / 61)$ \\
\hline
\end{tabular}

$\mathrm{SL}=$ São Luiz I, $\mathrm{P}=$ Palmital, $\mathrm{R}=$ Roque, and $\mathrm{U}=$ Ubá.
Note: The proportion of dogs converting from negative (ELISA-1) to positive (ELISA-2) serology was $0.59(17 / 29)$. of human VL. Nevertheless, the unanticipated expressive reversion rate for LST (0.38) obtained among people within one year of exposure suggests the possibility of individuals existing with short-lived memory T-cell controlling the DTH reaction to Leishmania antigens. Consistent with our data, some loss of LST antigen sensitivity and potency was found in a three-year follow-up of VL patients in Bangladesh. ${ }^{29}$ Interesting, the frequency of cases reverting from a positive ELISA-1 response to a negative ELISA-2 response remarkably decreased in the age group of $\geq 45$ years compared with the younger segment of the population. Whether these findings reflect an age-dependent variation in the elicited lasting T-cell memory controlling the antibody response remains unclear.

Protective immunity to leishmaniasis has been consistently associated with an antigen-specific $\mathrm{T}$ helper cytokine type 1 (Th1) immune response. ${ }^{30}$ In humans, a positive LST following natural exposure is thought to reflect resistance to infection, with genetic epidemiology studies demonstrating a strong genetic component for mounting a LST response. ${ }^{31}$ Furthermore, the tumor necrosis factor (TNF)-1 allele of the TNF- $\alpha$ gene, located in the class III region of human leukocyte antigen (HLA) has been shown to be associated with the development of a positive LST. ${ }^{32}$ In fact, distinct chromosomal regions may contain genes that control the DTH response as opposed to progressive VL. ${ }^{33}$ Here, we found a negative association between the positivity of DTH and the presence of specific antibodies in asymptomatic subjects (Table 6). Of note, among the 72 subjects who were LST negative at the first survey, 62 remained LST-2 negative; of these, 17 (27\%) converted from a negative to a positive serology response (considered as a potential susceptible host). In contrast, none of the 10 "immune" positive LST-2 subjects became seropositive at this time. Moreover, a number of leishmanin-positive subjects of all age groups had reverted to seronegativity at the ELISA-2. Collectively, our data support the contention that a positive DTH skin test response to Leishmania antigens reflects an effective cellmediated immune response in healthy individuals. Similarly, Bern and co-workers reported ${ }^{29}$ that a positive LST result in treated VL patients was strongly associated with protection against subsequent disease symptoms.

The lack of any significant differences in infection rates by gender or age (Table 3 ) indicates that 1 ) all of the population was at an equal risk of infection, and 2) most transmission of 
L. infantum to people occurred close to or within a human dwelling, and involved infected dogs as well. During the surveys, many canine cases of the disease occurred and sand fly catches made in the area indicated that Lutzomyia longipalpis was the most commonly found sand fly species ( $~ 80 \%$ of the collected samples) inside the house and in the peridomiciliary dependences, which may be implicated in the VL transmission in Pancas. It is interesting to note that the seroprevalences of both the human and canine L. infantum infections were highly variable, suggesting a large heterogeneity in the transmission of $L$. infantum within the study area. These findings may reflect distinct eco-epidemiologic features determined by changes in the sand fly densities and/or patterns of genetic differentiation among $\mathrm{Lu}$. longipalpis populations circulating in these localities.

Serologic test performance depends on many factors, such as infection status ${ }^{13,14}$ and the type of diagnostic antigen or conjugate used. ${ }^{17}$ In this researach, a L. infantum-based IFAT (using the same diagnostic cut-off titer as the reference values of the FUNASA laboratories) had a suboptimal sensitivity (35\%) for detecting parasite-positive dogs. Our findings corroborated the known high sensitivity of the ELISA. ${ }^{17,34}$ The data further validate our previous study, ${ }^{15}$ showing that the crude and recombinant leishmanial antigens must be used in parallel to obtain an assay with $100 \%$ sensitivity (Table 7). As previous studies reported high specificities (ranging from $94 \%$ to $100 \%$ ) of ELISAs using the rK39 and rK26, ${ }^{18,19}$ the latter test was used for estimating $L$. infantum infection in the surveys described here. Nearly $57 \%$ of the indigenous dogs had positive serology, thus revealing that the level of parasite transmission in Pancas is even higher than in other endemic areas in Brazil. ${ }^{34-37}$ The high seroconversion rate of the local dogs within one year of exposure (Table 8 ) is further evidence of the active peridomestic transmission of the parasite. Comparable results were obtained in a canine surveillance program (using introduced sentinel dogs and the native dog population) conducted in an endemic rural area of Colombia. ${ }^{37}$

Although control of VL has been achieved in some areas by 1) diagnosis and treatment of human cases, 2) elimination of infected dogs, and 3) vector control, these methods require constant vigilance to be effective. ${ }^{10,38}$ As a consequence, the relative ineffectiveness of these control measures represents another factor contributing to the increasing relevance of VL as a public health problem in Brazil (http://portal.saude.gov. br/ portal/arquivos/pdf/manual_leish_visceral2006.pdf). As in other surveys, ${ }^{3,4,7}$ in this study more than half of the seropositive dogs remained asymptomatic $(58 \%)$, whereas others developed either oligosymptomatic $(26 \%)$ or polisymptomatic $(16 \%)$ VL. During the cross-sectional serodiagnosis survey, all dogs with IFAT-determined titers of $\geq 1: 40$ and/ or with active disease were euthanized within 15 days after being diagnosed, but this commonly used test underestimated the true prevalence of canine infection and most cases were missed. However, the overall serology reversion rate $(62 \%)$ was nearly 4 times higher than that of seroconversion $(14 \%)$ among people within one year of exposure. These observations indicate that CVL is the major source of human VL by the transmission route dog-sand fly-human.

The culling program used by the local public health service has been ineffective in the study area. In general, a negative serologic result with crude leishmanial lysate does not discard the possibility of infection, because 1) classic diagnostic tests (such as IFAT) are insufficiently sensitive to detect early or asymptomatic infections, ${ }^{13,14,17}$ 2) there is a significant pre-patent period before seroconversion, ${ }^{4} 3$ ) a fraction of infected dogs may never convert, ${ }^{11}$ and 4 ) dogs may revert to seronegative but remain parasite positive. ${ }^{3}$ Therefore, the effectiveness of culling programs will depend ultimately on a reliable test for the routine serodiagnosis of CVL, ${ }^{39}$ and more efficient dog removal regimens than those used in practice by the FUNASA. ${ }^{7,10,35}$ As some dogs will spontaneously recover and may actually develop protective immunity to leishmanial reinfections, ${ }^{4}$ the most feasible approach to control the transmission cycle of zoonotic VL would seem to be an effective second-generation Leishmania $\mathrm{T}$-cell vaccine ${ }^{30}$ for canine use that will protect dogs from developing parasitemia and from becoming peridomestic reservoirs of the parasite. ${ }^{7}$

Received September 21, 2007. Accepted for publication September 19, 2008.

Acknowledgments: We thank Daniel Kiefer, Fundação Nacional da Saúde (Funasa, ES), for assistance in the field studies. The recombinant antigens K26 and K39 were kindly supplied by the Infectious Disease Research Institute (Seattle, WA).

Financial support: This work was supported in part by FIOCRUZ and the PRONEX $3 / \mathrm{CNPq}$ (National Council for Scientific and Technological Development of the Ministry of Science and Technology, Brazil). Gabriel Grimaldi Jr. and Elisa Cupolillo are CNPq Fellow researchers, Marcos V. Santos da Costa is a Master student in the Program in Parasite Biology/FIOCRUZ and sponsored by CNPq.

Authors' addresses: Aloísio Falqueto, Adelson L. Ferreira, and Claudiney B. dos Santos, Unidade de Medicina Tropical, Universidade Federal do Espírito Santo, Av. Marechal Campos 1468, Vitória, ES 29040-090, Brazil, E-mails: falqueto@npd.ufes.br, adelsonlf@ hotmail.com, and claudiney@ppgcf.ufes.br. Renato Porrozzi, Marcos V. Santos da Costa, Antonio Teva, Elisa Cupolillo, and Gabriel Grimaldi Jr, Laboratório de Pesquisas em Leishmaniose, Instituto Oswaldo Cruz, IOC/FIOCRUZ, Pavilhão Leônidas Deane-sala 509, Av. Brasil 4365, Rio de Janeiro, RJ 21045-900, Brazil, Tel: 55-213865-8203, Fax: 55-21-2209-4110, E-mails: mavicos2004@yahoo .com.br, porrozzi@ioc.fiocruz.br, teva@ioc.fiocruz.br, ecupoli@ioc .fiocruz.br, and grimaldi@ioc.fiocruz.br. Antonio Campos-Neto, The Forsyth Institute 140 The Fenway, Boston, MA 02115-3799, E-mail: Acampos@forsyth.org.

\section{REFERENCES}

1. Grimaldi G Jr, Tesh RB, McMahon-Pratt D, 1989. A review of the geographic distribution and epidemiology of leishmaniasis in the New World. Am J Trop Med Hyg 41: 687-725.

2. Quinnell RJ, Dye C, 1994. Correlates of the peridomestic abundance of Lutzomyia longipalpis (Diptera: Psychodidae) in Amazonian Brazil. Med Vet Entomol 8: 219-224.

3. Quinnell RJ, Courtenay O, Garcez L, Dye C, 1997. The epidemiology of canine leishmaniasis: transmission rates estimated from a cohort study in Amazonian Brazil. Parasitology 115: $143-156$.

4. Moreno J, Alvar J, 2002. Canine leishmaniasis: epidemiological risk and the experimental model. Trends Parasitol 18: 399-405.

5. Altet L, Francino O, Solano-Gallego L, Renier C, Sanches A, 2002. Mapping and sequencing of the canine NRAMPlgene and identification of mutations in leishmaniasis-susceptible dogs. Infect Immun 70: 2763-2771.

6. Quinnell RJ, Kennedy LJ, Barnes A, Courtenay O, Dye C, Garcez LM, Shaw MA, Carter SD, Thomson W, Ollier WER, 2003. Susceptibility to visceral leishmaniasis in the domestic dog is associated with MHC class II polymorphism. Immunogenetics 55: $23-28$. 
7. Tesh RB, 1995. Control of zoonotic visceral leishmaniasis: is time to change strategies? Am J Trop Med Hyg 52: 287-292.

8. Badaró R, Jones TC, Carvalho EM, Sampaio D, Reed SG, Barral A, Teixeira R, Johnson WD Jr, 1986a. New prospectives on a subclinical form of visceral leishmaniasis. J Infect Dis 154: 1003-1011.

9. Jeronimo SM, Teixeira MJ, Sousa A, Thielking P, Pearson RD, Evans TG, 2000. Natural history of Leishmania (Leishmania) chagasi infection in Northeastern Brazil: long term follow-up. Clin Infect Dis 30: 608-609.

10. Courtenay O, Quinnell RJ, Garcez LM, Shaw JJ, Dye C, 2002. Infectiousness in a cohort of Brazilian dogs: why culling fails to control visceral leishmaniasis in areas of high transmission. J Infect Dis 186: 1314-1320.

11. Dye C, Vidor E, Dereure J, 1993. Serological diagnosis of leishmaniasis: on detecting infection as well as disease. Epidemiol Infect 103: 647-656.

12. Fisa R, Riera C, Ribera E, Gállego M, Portús M, 2002. A nested polymerase chain reaction for dignosis and follow-up of human visceral leishmaniasis using blood samples. Trans $R$ Soc Trop Med Hyg 96: S1191-S1194.

13. Quinnell RJ, Courtenay O, Davidson S, Garcez L, Lambson B, Ramos P, Shaw JJ, Shaw MA, Dye C, 2001. Detection of Leishmania infantum by PCR, serology and immune response in a cohort study of Brazilian dogs. Parasitology 122: 253-261.

14. Reithinger R, Quinnell RJ, Alexander B, Davies CR, 2002. Rapid detection of Leishmania infantum infection in dogs: comparative study using an immunochromatographic dipstick test, enzymelinked immunosorbent assay, and PCR. J Clin Microbiol 40: 2352-2356.

15. Porrozzi R, Santos da Costa MV, Teva A, Falqueto A, Ferreira AL, Santos CD, Fernandes AP, Gazinelli RT, Campos-Neto A, Grimaldi G Jr, 2007. Comparative evaluation of enzyme-linked immunosorbent assays based on crude and recombinant leishmanial antigens for serodiagnosis of symptomatic and asymptomatic Leishmania infantum visceral infections in dogs. Clin Vaccine Immunol 14: 544-548.

16. Sokal JE, 1975. Measurement of delayed skin-test responses. N Engl J Med 293: 501-502.

17. Mettler M, Grimm F, Capelli G, Camp H, 2005. Evaluation of enzyme-linked immunosorbent assays, an immunoflurescentantibody test, and two rapid tests (immunochromatographicdipstick and gel tests) for serological diagnosis of symptomatic and asymptomatic Leishmania infections in dogs. J Clin Microbiol 43: 5515-5519.

18. Burns JM Jr, Shreffler WG, Benson DR, Ghalib HW, Badaró R, Reed SG, 1993. Molecular characterization of a kinesin-related antigen of Leishmania chagasi that detects specific antibody in African and American visceral leishmaniasis. Proc Natl Acad Sci USA 90: 775-779.

19. Bhatia A, Daifalla NS, Jen S, Badaró R, Reed SG, Skeike YA, 1999. Cloning, characterization and serological evaluation of $\mathrm{K} 9$ and K26: two related hydrophilic antigens of Leishmania chagasi. Mol Biochem Parasitol 102: 249-261.

20. Badaró R, Reed SG, Carvalho EM, 1983. Immunoflurescent antibody test in American visceral leishmaniasis: sensitivity and specificity of different morphological forms of two Leishmania species. Am J Trop Med Hyg 32: 480-484.

21. Cupolillo E, Brahim LR, Toaldo CB, Oliveira-Neto MP, Felinto de Brito ME, Falqueto A, Naiff MF, Grimaldi G Jr, 2003. Genetic polymorphism and molecular epidemiology of Leishmania (Viannia) braziliensis from different hosts and geographic areas in Brazil. J Clin Microbiol 41: 3126-3132.

22. Marty P, Lelievre A, Quaranta JF, Rahal A, Gari-Thoussaint M, Fichoux Y, 1994. Use of leishmanin skin test and Western blot analysis for epidemiological studies in visceral leishmaniasis areas: experience in a highly endemic focus in Alpes-maritimes (France). Trans R Soc Trop Med Hyg 88: 658-659.

23. Gramiccia M, Bettini S, Gradoni L, Ciarmoli P, Verrelli ML, Loddo S, Cicalo C, 1990. Leishmaniasis in Sardinia. 5. Leishmanin reaction in the human population of a focus of low endemicity of canine leishmaniasis. Trans R Soc Trop Med Hyg 84: 371-374.

24. Badaró R, Jones TC, Lourenço R, Cerf BJ, Sampaio D, Carvalho EM, Rocha H, Teixeira R, Johnson WD Jr, 1986b. A prospective study of visceral leishmaniasis in an endemic area of Brazil. J Infect Dis 154: 636-649.

25. Riera C, FISA R, Udina M, Gállego M, Portus M, 2004. Detection of Leishmania infantum cryptic infection in asymptomatic blood donors living in an endemic area (Eivissa, Balearic Islands, Spain) by different diagnostic methods. Trans $R$ Soc Trop Med Hyg 98: 102-110.

26. Evans TG, Teixeira MJ, Sousa AQ, Pearson RD, 1995. Short report: follow-up of the natural history of persons infected with Leishmania chagasi. Am J Trop Med Hyg 53: 360-361.

27. Falqueto A, Sessa PA, Ferreira AL, Vieira VP, Santos CB, Varejão JBM, Cupolillo E, Porrozzi R, Carvalho-Paes LE, Grimaldi G $\mathrm{Jr}, 2003$. Epidemiological and clinical features of Leishmania (Viannia) braziliensis American cutaneous and mucocutaneous leishmaniasis in Espírito Santo State, Brazil. Mem Inst Oswaldo Cruz 98: 1003-1010.

28. Zinkernagel RM, Ehl S, Aichele P, Oehen S, Kundig T, Hengartner $\mathrm{H}, 1997$. Antigen localisation regulates immune responses in a dose- and time-dependent fashion: a geographical view of immune reactivity. The anatomy of antigen-specific immune responses. Immunol Rev 156: 199-209.

29. Bern C, Amann J, Haque R, Chowdhury R, Ali M, Kurkjian KM, Vaz L, Wagatsuma Y, Breiman RF, Evan Secor W, Maguire JH, 2006. Loss of leishmanin skin test antigen sensitivity and potency in a longitudinal study of visceral leishmaniasis in Bangladesh. Am J Trop Med Hyg 75: 744-748.

30. Coler RN, Reed SG, 2005. Second-generation vaccines against leishmaniasis. Trends Parasitol 21: 244-248.

31. Shaw MA, Davies CR, Llanos-Cuentas EA, Collins A, 1995. Human genetic susceptibility and infection with Leishmania peruviana. Am J Hum Genet 57: 1159-1169.

32. Karplus TM, Jerônimo SM, Chang H, Helms BK, Burns TL, Murray JC, Mitchell AA, Pugh EW, Braz RF, Bezerra FL, Wilson ME, 2002. Association between the tumor necrosis factor locus and the clinical outcome of Leishmania chagasi infection. Infect Immun 70: 6919-6925.

33. Jerônimo SMB, Duggal P, Ettinger NA, Nascimento ET, Monteiro GR, Cabral AP, Pontes NN, Lacerda HG, Queiroz PV, Maia CG, Pearson RD, Blackwell JM, Beaty TH, Wilson ME, 2007. Genetic predisposition to self-curing infection with the protozoan Leishmania chagasi: a genome wide scan. J Infect Dis 196: 1261-1269.

34. Paranhos-Silva M, Freitas LAR, Santos WC, Grimaldi G Jr, Pontes-de-Carvalho LC, Oliveira-dos-Santos AJ, 1996. A crosssectional serodiagnostic survey of canine leishmaniasis due to Leishmania chagasi. Am J Trop Med Hyg 55: 39-44.

35. Ashford DA, David JR, Freire M, David R, Sherlock I, Eulálio MC, Sampaio DP, Badaró R, 1998. Studies on control of visceral leishmaniasis: impact of dog control on canine and human visceral leishmaniasis in Jacobina, Bahia, Brazil. Am J Trop Med Hyg 59: 53-57.

36. Evans TG,Teixeira MJ,McAuliffe IT,Vasconcelos IAB, Vasconcelos AW, Sousa AQ, Lima JWO, Pearson RD, 1992. Epidemiolgy of visceral leishmaniasis in northeast Brazil. J Infect Dis 166 : 1124-1132.

37. Corredor A, Gallego JF, Tesh RB, Morales A, Carrasquilla CF, Young DG, Kreutzer RD, Boshell J, Palau MT, Caceres E, Pelaez D, 1989. Epidemiology of visceral leishmaniasis in Colombia. Am J Trop Med Hyg 40: 480-486.

38. Davies CR, Kaye P, Croft SL, Sundar S, 2003. Leishmaniasis: new approaches to disease control. BMJ 326: 377-382.

39. Boarino A, Scalone A, Gradoni L, Ferroglio E, Vitale F, Zanatta R, Giuffrida MG, Rasati S, 2005. Development of recombinant chimeric antigen expressing immunodominant B epitopes of Leishmania infantum for serodiagnosis of visceral leishmaniasis. Clin Diagn Lab Immunol 12: 647-653. 